\title{
Clarification of the role of the cerebral ventricles in cholinergically induced drinking
}

\section{THEODORE J. CICERO and ROBERT D. MYERS, Laboratory of Neuropsychology, Purdue University, Lafayette, Ind. 47907}

Recently, we found that polydipsia is not produced when carbachol (carbamyl choline) is injected repeatedly in a wide range of doses into the cerebral ventricles of unrestrained rats (Myers \& Cicero, 1968). In his excellent comment on the possibility that the ventricular system could be involved in certain responses to chemical stimulation of the brain, Routtenberg (1968) has emphasized the importance of considering the dose-response factor in connection with cholinergically induced drinking. In particular, the question raised was whether the absence of excessive drinking in our experiment was due to cumulative build-up of carbachol in the rat's ventricle.

In our original paper, the lowest of the five doses of carbachol used was inadvertently expressed in the text as $3.40 \times 10^{-10}$ moles. It is clear from the figure legend, however, that during the last infusion sequence (Period $G$ ) a dose of $10.88 \times 10^{-10}$ moles was micro-injected twice per day at a $12 \mathrm{~h}$ interval; thus, the lowest dose of carbachol given over a 24 h period was $21.77 \mathrm{x}$ $10^{-10}$ moles $(3.2 \mu \mathrm{g})$ and not $12 \mu \mathrm{g}$ per day.

Because of the complexity of our experiment and because "stimulus-bound" drinking did not occur at any dose of carbachol, data on hourly measures of water intake were omitted from our original paper. Since these negative findings have an important bearing on this issue, however, Table 1 is presented to show the hourly fluid intakes for two representative micro-infusion schedules: the $1.6 \mu \mathrm{g}$ per $\mathrm{h}$, and the same dose delivered consecutively at $12 \mathrm{~h}$ intervals. From these results, it is apparent that neither dose produced an alteration in normal water intake in the hours immediately following individual micro-injections. Moreover, there were no signs of toxic side-effects at these dose levels; fluid intakes failed to increase and decreased only at the highest dose, and then after 24 to $48 \mathrm{~h}$ had elapsed.

An additional consideration is the enormous dilution of each of the carbachol solutions administered in our original experiment. The volume of cerebrospinal fluid contained in the cerebral ventricles of the rat, as determined by cisternal sampling (Reed et al, 1967) as well as by vinylite casting (McFarland \& Morgane, personal communication) ranges between 120 to $500 \mu \mathrm{l}$. Therefore, it would appear that the effective doses employed in our study are far less than those conventionally used to evoke polydipsia by crystalline carbachol stimulation. Finally, in view of the negative findings of Coury (1967), Khavari et al (1968) and Myers \& Yaksh (1968), it is now clearly substantiated that carbachol induced drinking is neurologically "circuit specific" and not mediated by the cerebral ventricular route.

\section{REFERENCES}

COURY, J. N. Neural correlates of food and water intake in the rat. Science, $1967,156,1763-1764$.
Table 1

Intake of Water Expressed in Milliliters Following Micro-injections in Rats of $1.6 \mu \mathrm{g}$ Twice per Dày at a 12-h Interval (top) and 1.6 $\mu \mathrm{g}$ each Hour (bottom). (S: Saline Control Rats; C: Carbachol-injected Rats)

\begin{tabular}{lllllll} 
& \multicolumn{5}{c}{ Hours } & \\
\cline { 2 - 7 } Animal & 1 & 2 & 3 & 4 & 5 & 6 \\
\hline S1 & 2 & 3 & 2 & 0 & 0 & 2 \\
S2 & 0 & 0 & 0 & 1 & 0 & 0 \\
C3 & 0 & 2 & 0 & 1 & 0 & 1 \\
C4 & 0 & 0 & 0 & 2 & 0 & 1 \\
C5 & 0 & 0 & 1 & 0 & 0 & 0 \\
C6 & 0 & 2 & 0 & 0 & 2 & 1 \\
S7 & 0 & 3 & 0 & 1 & 1 & 1 \\
C8 & 2 & 2 & 1 & 0 & 1 & 1 \\
C9 & 1 & 1 & 1 & 2 & 1 & 1 \\
C10 & 0 & 1 & 0 & 2 & 0 & 0 \\
C11 & 0 & 2 & 1 & 0 & 0 & 0 \\
\hline S1 & 2 & 0 & 2 & 3 & 2 & 3 \\
S2 & 0 & 0 & 2 & 3 & 2 & 3 \\
C3 & 3 & 0 & 5 & 0 & 1 & 0 \\
C4 & 1 & 1 & 0 & 2 & 1 & 0 \\
C5 & 3 & 1 & 0 & 1 & 1 & 0 \\
C6 & 1 & 1 & 1 & 0 & 1 & 2 \\
S7 & 2 & 1 & 1 & 1 & 0 & 0 \\
C8 & 3 & 1 & 0 & 1 & 0 & 0 \\
C9 & 2 & 2 & 2 & 0 & 0 & 0 \\
C10 & 2 & 0 & 0 & 1 & 0 & 3 \\
C11 & 1 & 0 & 0 & 1 & 0 & 2 \\
\hline
\end{tabular}

KHAVARI, K. A, HEEBINK, P., \& TRAUPMAN, J. Effects of intraventricular carbachol and eserine on drinking. Psyehonomic Science, $1968,11,93-94$.

MYERS, R. D., \& CICERO, T. J. Are the cerebral ventricles involved in thirst produced by a cholinergic substance? Psychonomic Science, 1968, 10, 93-94.

MYERS, R. D., \& YAKSH, T. L. Feeding and temperature responses in the unrestrained rat after injections of cholinergic and aminergic substances into the cerebral ventricles. Physiology \& Behavior, 1968 , in press.

REED, D. J., WITHROW, C. D., \& WOODBURY, D. M. Electrolyte and acid-base parameters of rat cerebrospinal fluid. Experimental Brain Research, 1967, 3, 212-219.

ROUTTENBERG, A. Dose-response problem in testing the ventricular hypothesis: Reply to Myers and Cicero. Psychonomic Sejence, 1968, 11 , 106. 